\title{
Metabolite secretion in microorganisms: the theory of metabolic overflow put to the test
}

\author{
Farhana R. Pinu ${ }^{1}$. Ninna Granucci ${ }^{2}$ James Daniell2,3 Ting-Li Han $^{2} \cdot$ Sonia Carneiro ${ }^{4} \cdot$ Isabel Rocha $^{4} \cdot$ Jens Nielsen $^{5,6}$. \\ Silas G. Villas-Boas ${ }^{2}$
}

Received: 10 November 2017 / Accepted: 7 February 2018

C Springer Science+Business Media, LLC, part of Springer Nature 2018

\begin{abstract}
Introduction Microbial cells secrete many metabolites during growth, including important intermediates of the central carbon metabolism. This has not been taken into account by researchers when modeling microbial metabolism for metabolic engineering and systems biology studies.

Materials and Methods The uptake of metabolites by microorganisms is well studied, but our knowledge of how and why they secrete different intracellular compounds is poor. The secretion of metabolites by microbial cells has traditionally been regarded as a consequence of intracellular metabolic overflow.

Conclusions Here, we provide evidence based on time-series metabolomics data that microbial cells eliminate some metabolites in response to environmental cues, independent of metabolic overflow. Moreover, we review the different mechanisms of metabolite secretion and explore how this knowledge can benefit metabolic modeling and engineering.
\end{abstract}

Keywords Microbial metabolism $\cdot$ Microorganisms $\cdot$ Active efflux $\cdot$ Secretion $\cdot$ Metabolic engineering $\cdot$ Metabolic modeling $\cdot$ Systems biology

Electronic supplementary material The online version of this article (https://doi.org/10.1007/s11306-018-1339-7) contains supplementary material, which is available to authorized users.

Farhana R. Pinu

Farhana.Pinu@plantandfood.co.nz

1 The New Zealand Institute for Plant and Food Research Limited, Private Bag 92169, Auckland 1142, New Zealand

2 School of Biological Sciences, University of Auckland, Private Bag 92019, Auckland, New Zealand

3 LanzaTech, Skokie, IL 60077, USA

4 Center of Biological Engineering, University of Minho, Campus de Gualtar, 4710-057 Braga, Portugal

5 Department of Biology and Biological Engineering, Chalmers University of Technology, Kemivagen 10, 41296 Gothenburg, Sweden

6 Novo Nordisk Foundation Center for Biosustainability, Technical University of Denmark, 2970 Hørsholm, Denmark

\section{Introduction}

Microorganisms have been used for the production of industrially relevant compounds for many years. Corynebacterium glutamicum and its mutants have been employed for the large-scale industrial production of glutamate, lysine and other flavor active amino acids (Hermann and Krämer 1996; Krämer 1994, 2004). Aspergillus niger is utilized for the fermentative production of citric acid, accounting for more than $90 \%$ of total citrate production worldwide (Soccol et al. 2006). Another industrially significant metabolite, succinic acid, has been produced in large quantities by microorganisms including Actinobacillus succinogenes, $C$. glutamicum, Escherichia coli and some genetically modified yeasts (Liang et al. 2013; Agarwal et al. 2006). Consequently, numerous studies have focused on the characterization of metabolic pathways and the development of tools to manipulate these pathways in order to increase product yield (Hermann and Krämer 1996; Ljungdahl and DaignanFornier 2012; Wendisch et al. 2006). Metabolite secretion is useful for industrial production as it simplifies the downstream extraction and purification of metabolites of interest (Krämer 2004, 1996). 
The transport of substrates into the cell has been the subject of many studies (Düring-Olsen et al. 1999; Magasanik and Kaiser 2002; Nehls et al. 2001; Schweikhard and Ziegler 2012). Comparatively, very little is known about the mechanisms of secretion of intracellular metabolites, especially primary metabolites. The secretion of metabolites is an essential biochemical function and reflects the internal metabolic state of the cell in response to environmental conditions (Krämer 1994; Chubukov et al. 2014). This process allows the removal of cell metabolic by-products from the intracellular medium in order to maintain homeostasis.

Most metabolite secretions are believed to result from imbalanced intracellular metabolic pathways causing an overflow of pathway intermediates and secretion of these metabolites due to intracellular accumulation (Paczia et al. 2012; Reaves et al. 2013). Metabolic overflow is a phenomenon commonly observed in many microorganisms, usually when the rate of glycolysis exceeds a critical value (Valgepea et al. 2010; Vemuri et al. 2006a; Fu et al. 2014). Under fully aerobic and substrate-rich conditions, most microbial cells use inefficient metabolic routes and convert a substantial amount of accessible carbon to incompletely oxidized endproducts such as ethanol, acetate and lactate (Molenaar et al. 2009; Tempest and Neijssel 1979). However, the concept of metabolic overflow cannot explain the secretion of many metabolites observed in time-series studies with parallel measurement of intracellular and extracellular metabolites (Krämer 1994; Carneiro et al. 2011, 2012; Han et al. 2013; Granucci et al. 2015). We often observe some metabolites being directly excreted to the extracellular medium without intracellular accumulation in response to environmental cues (Carneiro et al. 2011; Han et al. 2013; Granucci et al. 2015). This scenario is most obvious when toxic metabolites are actively secreted by the cell using different efflux pumps (Becker et al. 2013; Forsberg and Ljungdahl 2001; Segura et al. 2012). However, other metabolites can be secreted following intracellular metabolic overflow under one environmental condition while they are exported without intracellular accumulation under another. Both metabolic overflow and active efflux (secretion without a intracellular accumulation) processes are behind of metabolite secretion; however, their mechanisms of regulation, especially when not following metabolic overflow, are still unclear.

Here, we review the mechanisms of metabolite secretion and revisit the concept of metabolic overflow. By re-analyzing published time-series metabolomics data, we demonstrate that the secretion of many intracellular metabolites cannot always be explained by intracellular metabolic overflow. We argue that a yet-unknown cellular strategy for the regulation of intracellular metabolite levels may drive the active secretion of some intracellular metabolites. Finally, we discuss the impact of these secretion mechanisms on metabolic modeling.

\section{Mechanisms of metabolite secretion by microorganisms}

The study of microbial transport mechanisms has primarily focused on uptake systems (Shlykov et al. 2013). Efflux transport has received much less attention despite its immense relevance to industrial processes (Van Dyk 2008). The exceptions are the study of multidrug efflux pumps in bacteria and fungi due to their role in drug-acquired resistance (Poole 2004; Martín et al. 2005), $\mathrm{Na}^{+} / \mathrm{H}^{+}$antiporter (Verkhovskaya et al. 2001; Kinclova-Zimmermannova and Sychrova 2007), metals transporters e.g. $\mathrm{Cu}^{+} / \mathrm{Ag}^{+}$efflux pump (Franke et al. 2003) and the macromolecule secretion systems (Shlykov et al. 2013). The study of primary metabolite secretion mechanisms in microorganisms has been limited mostly to a handful of amino and non-amino organic acids of industrial interest (Krämer 1994; Van Dyk 2008; Velasco et al. 2004; Netik et al. 1997).

Efflux transport mechanisms are similar to those involved in metabolite uptake (Box 1). The secretion or efflux of intracellular metabolites to outside the cell occurs through active or passive mechanisms. Passive transport is not concentrative in nature and it is rather equilibrative of transmembrane thermodynamic activities (Kell and Oliver 2014). Passive secretion is carried out either through the cell membrane (lipoidal diffusion) or with the help of transporters (facilitated diffusion) (Fig. 1a) and it occurs for most non-charged molecules and depends on the hydrophobicity of the solute and the properties of the membrane (Konings et al. 1992). This is believed to be the mechanism of secretion for some small metabolites, particularly fermentation end-products such as alcohols, ketones and small organic acids (Ingram 1976; Walter and Gutknecht 1984). Organic acids are membrane permeable in the undissociated form; thus, diffusion depends on cytosol pH (Kell et al. 1981). Hydrophobic and branched-chain amino acids can also permeate the plasma membrane through passive diffusion (through the bilayer) (Fig. 1) (Driessen and Konings 1990). For example, proline overproducing strains of E. coli K12 or Bacillus subtilis generate a proline gradient of sufficient magnitude across the cytoplasmic membrane to support proline diffusion (Hoffmann et al. 2012; Rancourt et al. 1984). Although it is still a matter of debate if passive secretion/uptake occurs through the bilayer or not (Kell and Oliver 2014; Smith et al. 2014), there are enough literature evidence that support the existence of both passive lipoidal (through bilayer) and carrier mediated (facilitated) diffusion (Lepore et al. 2011; Nikaido 1993). 
Secretion can also occur through specific transporters/carriers present in the cell membrane. Passive secretion occurring through channels or carriers is referred to as protein-mediated diffusion and this type of efflux can be observed when microbial cells react to hypo-osmotic stress. In this case, osmotic downshock releases a variety of metabolites such as proline, glutamate and glycine by stretching an activated channel (Lamark et al. 1992). Carriers are also involved in active secretion, a process where energy is used to drive metabolite efflux against its electrochemical gradient (Fig. 1b). The most-studied primary active efflux transporters utilize the hydrolysis of ATP. For instance, ABC exporters or ATP-binding cassette transporter proteins are widely used by cells to perform drug extrusion and also to excrete some primary metabolites (Lamark et al. 1992). Secondary active systems transport a second solute by harvesting energy obtained from the primary transport and can be classified as uniporters, symporters and antiporters (Saier Jr 2000; Forrest et al. 2011). These three basic mechanisms of transport represent the main mechanisms known for microbial efflux (Van Dyk 2008).

Table 1 summarizes some transporters known to secrete primary metabolites in C. glutamicum, E. coli, S. cerevisiae and A. niger; and a few of these are underlined below.
Mechanisms for the secretion of amino acids are well studied in $C$. glutamicum and E. coli because of their industrial relevance (Wachi 2013; Eggeling and Sahm 2003; Kell et al. 2015). Consequently, important amino acid excretion systems have been characterized using these organisms as models. For example, $C$. glutamicum secretes L-lysine by secondary secretion in which cationic lysine is co-transported with two hydroxide ions (Krämer 1994). The transporter LysE identified in 1996 by Vrljic et al. is responsible for this transport as well as it appears to be involved in the secretion of arginine (Vrljic et al. 1996).

Despite the fact that approximately 2.1 million tons of monosodium glutamate is produced annually using $C$. glutamicum (Ajinomoto 2009), the secretion mechanism for L-glutamate has only recently been described as occurring via small-conductance mechanosensitive channels (Becker et al. 2013; Nakamura et al. 2007; Mitsuhashi 2014). This mechanism is triggered by alterations in cell membrane tension and prevents cell disruption by the fast release of small internal solutes (Becker et al. 2013; Bass et al. 2002). This explains why industrial techniques to influence the stability of the membrane of $C$. glutamicum, such as biotin limitation and the addition of some surfactants, lead to increased glutamate excretion (Burkovski and Krämer 2002). Moreover, it is now well known that the activation of mechanosensitive

Table 1 Primary metabolites and their respective secretion transporters in different microorganisms

\begin{tabular}{|c|c|c|c|c|}
\hline Microorganism & Metabolite & Transporter & Mechanism & Reference \\
\hline \multirow[t]{5}{*}{ Corynebacterium glutamicum } & L-Lys, L-Arg & LysE & Secondary active secretion & $\begin{array}{l}\text { Vrljic et al. (1996), Stäbler et al. } \\
\text { (2011) }\end{array}$ \\
\hline & L-Thr, L-Ser & ThrE & Secondary active secretion & $\begin{array}{l}\text { Eggeling and Sahm, (2003), } \\
\text { Simic et al. (2001) }\end{array}$ \\
\hline & L-Iso, L-Met, Leu, Val & BrnEF & Secondary active secretion & $\begin{array}{l}\text { Nakamura et al. (2007), } \\
\text { Trötschel et al. (2005) }\end{array}$ \\
\hline & Glu & YggB/ NCgl1221 & Protein-mediated diffusion & $\begin{array}{l}\text { Nakamura et al. (2007), Becker } \\
\text { et al. (2013) }\end{array}$ \\
\hline & Succinate & SucE1 & Secondary active secretion & Fukui et al. (2011) \\
\hline \multirow[t]{7}{*}{ Escherichia coli } & Aromatic amino acids & YddG & Secondary active secretion & Airich et al. (2010) \\
\hline & Thr/homoserine & RhtA(YbiF) & Secondary active secretion & $\begin{array}{l}\text { Simic et al. (2001), Livshits } \\
\text { et al. (2003) }\end{array}$ \\
\hline & L-Glu & $\mathrm{Yggb} / \mathrm{MscS}$ & Protein-mediated diffusion & $\begin{array}{l}\text { Broda, (1968), Börngen et al. } \\
\text { (2010) }\end{array}$ \\
\hline & $\begin{array}{l}\text { L-Cys and components of the } \\
\text { cysteine pathway }\end{array}$ & YdeD & Secondary active secretion & Daßler et al. (2000) \\
\hline & L-Cys, $O$-acetylserine & YfiK & Secondary active secretion & Franke et al. (2003 \\
\hline & Lactose and glucose & SetA, SetB & Secondary active secretion & Liu et al. (1999) \\
\hline & $\gamma$-Hydroxybenzoate & $\mathrm{AaeB}$ & Secondary active secretion & Van Dyk et al. (2004) \\
\hline \multirow[t]{2}{*}{ Saccharomyces cerevisiae } & Glycerol & FPS1 & Protein-mediated diffusion & $\begin{array}{l}\text { Beese-Sims et al. (2011), Geijer } \\
\text { et al. (2012) }\end{array}$ \\
\hline & $\begin{array}{l}\text { Homoserine, Thr, Asp, Glu, } \\
\text { Ala }\end{array}$ & Aqr1 & Secondary active secretion & Velasco et al. (2004) \\
\hline Aspergillus niger & Citric acid & ATP pump & Primary active secretion & Netik et al. (1997) \\
\hline
\end{tabular}


glutamate efflux pump (encoded by a gene called NCgl1221) occurs due to the change in membrane tension (Mitsuhashi 2014).

While aromatic amino acids are usually secreted by passive diffusion in C. glutamicum (Burkovski and Krämer 2002), an aromatic amino acid exporter has been characterized in E. coli by Airich et al. (2010), and it is assumed to be the major exporter for this class of amino acids. L-glutamate in E. coli seems to be secreted by the same channel mechanism (known as mscS) found in C. glutamicum (Becker et al. 2013; Wachi 2013). Similar excretion mechanisms are known to be involved in the secretion of many amino acids including lysine, isoleucine, threonine, methionine and others (Van Dyk 2008). In addition, sugar efflux transporters have been identified in $E$. coli. These can transport lactose and glucose as well as other sugar derivatives. However, it has been suggested that the genes encoding these are either poorly expressed or made redundant by other proteins with the same function in $E$. coli (Liu et al. 1999).

$S$. cerevisiae is used as a model eukaryote for genetics and cell biology. However, we know little about its primary metabolite secretion mechanisms, despite its widespread use in industrial fermentation processes. The latest comprehensive metabolite secretion study explores internal membrane transporter Aqr1 that works as an amino acid/ $\mathrm{H}^{+}$antiporter (Velasco et al. 2004). This transporter is the major excretion system for homoserine and $\mathrm{L}$-threonine, and increases the secretion of L-alanine, L-aspartate and L-glutamate when overexpressed. Unlike the bacterial transporters, $S$. cerevisiae does not secrete amino acids directly, but instead loads them into intracellular vesicles, which merge with the cytoplasmic membrane, releasing the amino acids to the extracellular environment (Velasco et al. 2004). In addition, $S$. cerevisiae has been widely used as an experimental model to explore the transport mechanisms of different drugs/drug resistance and in toxicogenomics studies (dos Santos and Sa-Correia 2011, 2015; dos Santos et al. 2014)

A. niger is another eukaryote commonly used in industrial fermentation, mostly for the production of citric acid. Citrate secretion has been demonstrated to occur actively through an ATP-dependent transporter (Netik et al. 1997), and also through passive diffusion during low extracellular $\mathrm{pH}$ (Mattey 1992), which is generally the case in industrial production. Many other secretion mechanisms for other metabolites in A. niger have been hypothesized, but most of them have not been demonstrated experimentally.

While here we mainly discussed primary metabolite secretion by industrially important microorganisms, it is noteworthy that metabolite secretion is also an important phenomenon for the ecosystems (Ponomarova and Patil 2015). In microbial communities, many microorganisms exhibit synergistic relationships and depends on each other to survive (Braga et al. 2016). For instance, metabolites secreted by one microbe are used as a nutritional source by another microbe and some harmful metabolites can be used by certain microbes, thus assisting other microbes within the community to survive (Schink 2002).

Microbial efflux systems have generally been studied in isolation, often in an artificial system with a focus on the secretion mechanism itself. This omits the complexity of the living organism. For full understanding, secretion mechanisms should be also investigated through a systems biology approach. 


\section{Box 1: Basis of metabolite secretion mechanism}

a

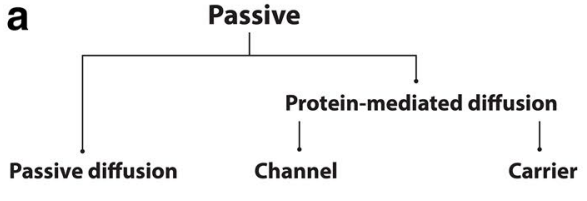

b

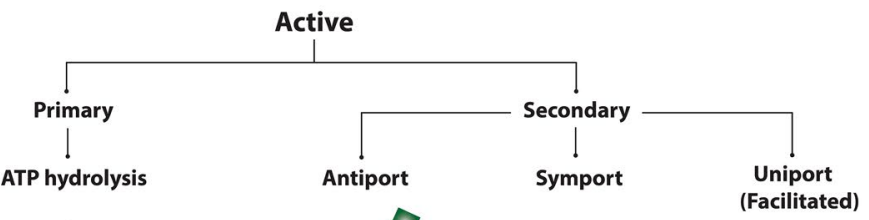

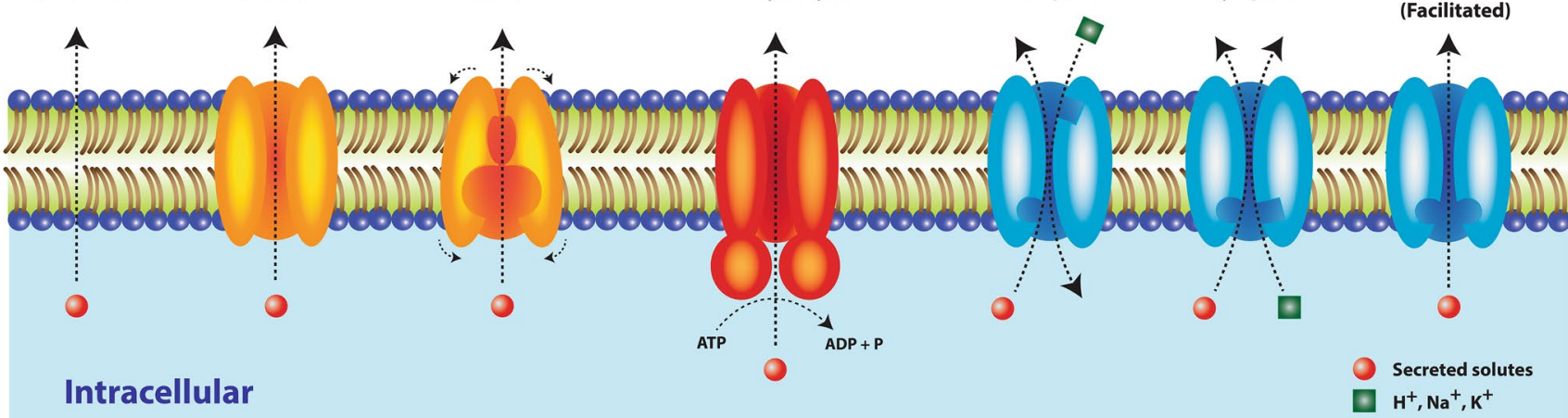

Fig. 1 Basic mechanisms for metabolite secretion, divided between passive and active. The figure shows passive diffusion through the membrane and protein-mediated diffusion by channel and carrier as

The basis of transport mechanism is almost the same for uptake and efflux systems, but it occurs in opposite directions and can be an active or passive process. Passive secretion (Fig. 1a), when the metabolite is secreted in the direction of its chemical or electrochemical gradient, is carried out through the cell membrane or specific structures (lipoidal diffusion); the former is used by most non-charged molecules. Passive secretion can also occur through specific transporters also known as transport systems, porters, permease systems, and permeases; these refer to a protein or protein complex which catalyzes a vectorial reaction (Saier Jr et al. 2006). Transporters can be divided into two main categories: channels and carriers (Saier Jr et al. 2006). The Transporter Classification Database is a useful resource which comprehensively classifies transporters based on phylogenetic and functional information (Saier Jr et al. 2006) (http://www.tcdb.org/). Channels are proteins that create a narrow hydrophilic passage that allows a range of molecules to pass through, usually ions and other small molecules. In contrast, carriers are substrate-specific in their interaction and possess a lower transport rate. In carrier-type facilitated diffusion, the transport process occurs through conformational changes in the carrier where the solute binding site can be exposed to one side of the membrane or the other (Boudker and Verdon 2010; West 1997). Passive secretion occurring through channels or carriers is referred to as protein-mediated diffusion. a passive secretion (yellow). The primary (red) and secondary (blue) active secretion mechanisms are represented by the ATP pump and antiport, symport and uniport, respectively

Unlike channels, carriers are also involved in active secretion (Fig. 1b), a process where additional energy is used to drive metabolite efflux against its gradient of concentration. Active secretion mechanisms are classified based on the type of energy used by the carrier. Two major classes are present in efflux systems: the primary active transporters, which require ATP hydrolysis, oxidation-reduction reactions or light as an energy source (not reversible); and secondary active transporters, which rely on the sum of transmembrane electrochemical gradients of all solutes, for example, protons, or sodium ions to drive the secretion of a metabolite (Saier Jr 2000). Secondary active systems harvest energy obtained from the transport of one solute down its electrochemical gradient to transport a second solute and might be reversible (Saier Jr 2000). This system is called secondary because, in the sequence of the events, the electrochemical gradient needs to be generated by primary mechanisms (Forrest et al. 2011). Well-known secondary mechanisms are uniport, symport and antiport systems. Uniport system transports a single metabolite down its electrochemical gradient, also called facilitated diffusion. Symport secretion uses the energy generated by the transport of a molecule to secrete, in the same direction, a second molecule; whereas antiport systems use downhill secretion energy as a driving force to transport a second molecule in the opposite direction. 


\section{Metabolic overflow}

The concept of metabolic overflow was first explored by Herbert Crabtree in 1929 when describing the carbohydrate metabolism of tumor cells and it has been widely used to justify the secretion of intracellular metabolites. Crabtree observed the production of lactate by tumor cells under aerobic conditions and an excess of glucose (Crabtree 1929). This phenomenon of aerobic fermentation is now known as the Crabtree effect and is found in many different cell types and microorganisms, primarily during growth under high sugar concentrations (Pronk et al. 1996; Chumnanpuen et al. 2014). Metabolic overflow was first seen as a consequence of the Crabtree effect, and has been defined as a phenomenon which occurs during growth under high substrate concentration or during the transition from a substrate-limited to a substrate rich condition as well as during nutrient scarcity (Box 2, Fig. 2) (Neijssel and Tempest 1976; Pronk et al. 1996; Hagman et al. 2014). However, metabolic overflow goes beyond this and, in addition to the major fermentation products, includes the secretion of many primary metabolites. For instance, Staphylococcus aureus shows a strainspecific overflow metabolism by secreting isoleucine and a few other organic acids in culture medium used for infection related studies (Dörries and Lalk 2013). Often, metabolic overflow occurs when microbial growth is limited by an essential nutrient, or when the uptake of a substrate is not regulated efficiently (Burkovski and Krämer 2002). For example, Bacillus subtilis produces overflow metabolites including acetate, diacetyl and acetoin when growing in phosphate-limited chemostats (Sonenshein 2007). There is a trend of associating metabolic overflow with overall secretion of intracellular metabolites to the extracellular medium (Paczia et al. 2012; Dörries and Lalk 2013). For instance, the secretion of 30-40 primary metabolites by four different microorganisms (S. cerevisiae, E. coli, Bacillus licheniformis and $C$. glutamicum) has been referred to as a consequence of extended metabolic overflow (Paczia et al. 2012).

Metabolic overflow has been mostly studied in the model microorganisms E. coli and S. cerevisiae (Box 2, Fig. 2). In E. coli, the massive secretion of acetate is observed during aerobic growth under high glucose concentrations, and many other metabolites such as pyruvate and glucose-6-phosphate will overflow in smaller quantities (Paczia et al. 2012). On the other hand, S. cerevisiae produces ethanol and glycerol as major metabolic by-products when growing aerobically on high sugar concentration (Hagman et al. 2014). The production of glycolytic NADH exceeds the cellular capability for its oxidation and results in reduced conditions; consequently, $S$. cerevisiae reduces pyruvate to ethanol or dihydroxyacetone phosphate to glycerol to maintain the redox balance (Box 2). Depending on the carbon source and other substances available during growth, $C$. glutamicum is capable of producing various overflow metabolites such as pyruvate when grown on lactate (Cocaign-Bousquet and Lindley 1995), dihydroxyacetone and lactate when grown on fructose (Kiefer et al. 2004), and glutamate when growing on biotin limited media or in the presence of penicillin and other surfactants (Burkovski and Krämer 2002). The filamentous fungus $A$. niger is known to secrete massive amounts of citric acid when growing on high sucrose concentrations under limited nitrogen, phosphate and metal ion conditions (Mattey 1992). Citrate overflow in A. niger mainly occurs because of unobstructed metabolic flow through glycolysis that increases the production of acetyl-CoA and oxaloacetate, thus increasing the production and secretion of citrate from the condensation of these two TCA cycle precursors using citrate synthase found in the mitochondria (Kiefer et al. 2004; Legiša and Mattey 2007). Some studies point to the limited capacity of several citrate metabolizing enzymes, including aconitase and isocitrate dehydrogenase, as key factors responsible for citric acid accumulation in $A$. niger (Crabtree 1929). However, this has been controversial (Legiša and Mattey 2007; Kubicek 1987). The role of different trace metals has also been highlighted (Shankaranand and Lonsane 1994), and a recent hypothesis suggests a tricarboxylate transporter that directly competes with aconitase for citrate, pumping citrate outside the mitochondria and increasing the rate of citric acid secretion to the extracellular environment (Kubicek 1987).

These typical examples of metabolic overflow explain the secretion of the major fermentation products usually found at $\mathrm{g} / \mathrm{L}$ scale in the spent culture media (e.g. ethanol, acetate, lactate, glycerol and citrate) (Box 2). However, the concept of overflow metabolism is often used to indiscriminately explain or interpret the secretion of all intracellular metabolites found in spent culture media (Mo et al. 2009). We believe this is not appropriate. Metabolic overflow is a reasonably well-characterized phenomenon and is likely to be involved in the secretion of many intracellular metabolites as well as major fermentation products. Nevertheless, metabolic overflow is not the only reason cells secrete intracellular metabolites. Time-series metabolomics experiments with concomitant measurement of intracellular and extracellular metabolites are the best way to study patterns of metabolite secretion. 


\section{Box 2: Metabolic overflow}

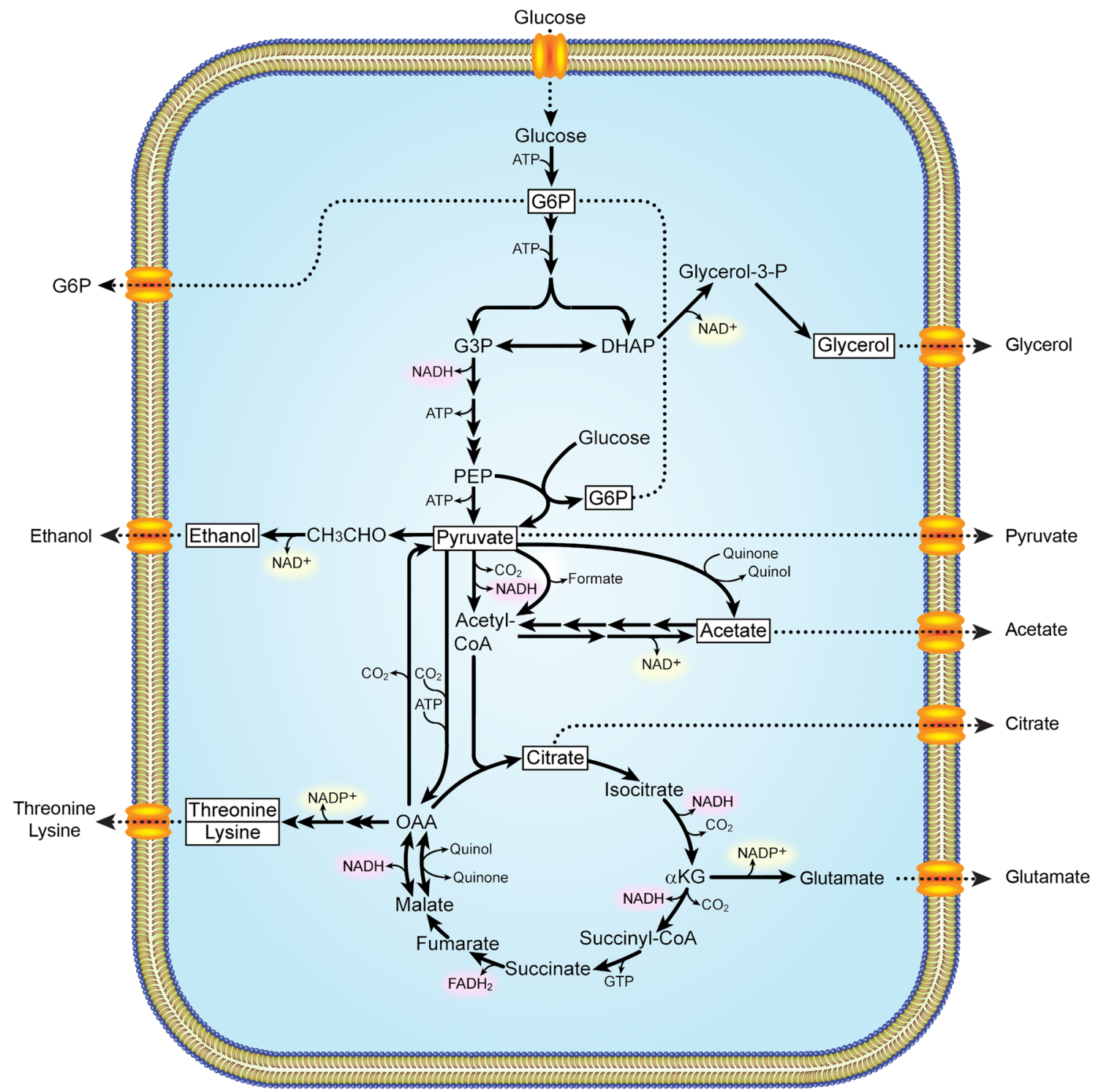

Fig. 2 Typical metabolic overflow of major fermentation intermediates in a microbial cell. Microorganisms secrete many metabolites outside the cell (highlighted in white) due to the intracellular

Metabolic overflow is typically described as a phenomenon where microorganisms secrete metabolic intermediates (e.g. ethanol, glycerol and acetic acid) while growing on high substrate concentration (Fig. 2). It is usually observed in microorganisms when they use energy-inefficient metabolic routes by expressing their fermentative behaviour, even though they are capable of using energy efficient respiratory pathways (Molenaar et al. 2009). Most early studies clearly indicate that the extent of metabolic overflow and the nature of excreted metabolites accumulation (shown in boxes). The oxidation-reducing reactions of cofactors in different central carbon metabolic pathways are also highlighted (yellow/pink)

depend on the carbon source used (Tempest and Neijssel 1979; Crabtree 1929; Neijssel and Tempest 1975; Holme 1957). Recent studies reveal that metabolic overflow mainly occurs when there is an imbalance between the fluxes of carbon uptake, energy production and biosynthesis (Molenaar et al. 2009; Holme 1957). Among the various parameters studied, redox balance seems to be the major force behind metabolic overflow (van Hoek and Merks 2012; Vemuri et al. 2006b) (Fig. 2). 
a

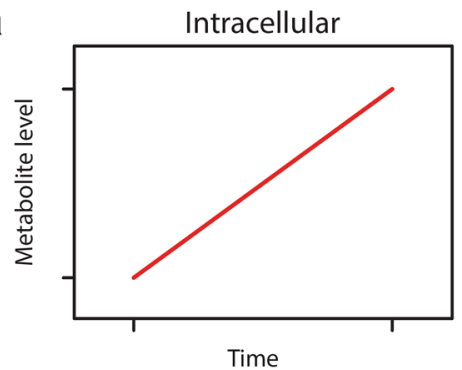

b

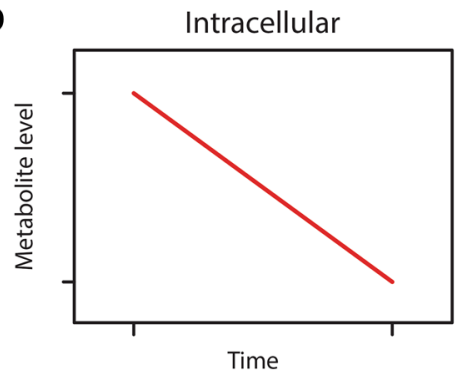

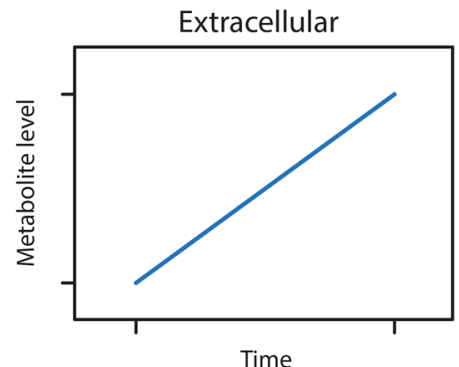

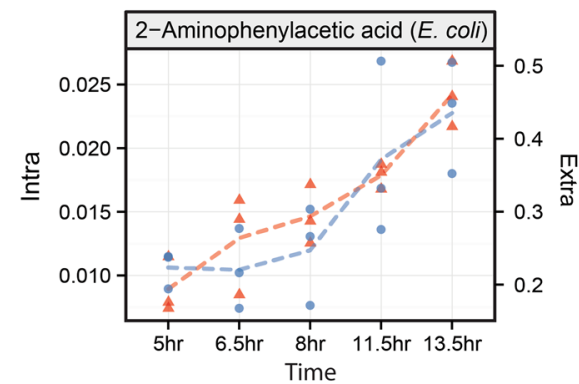

罯

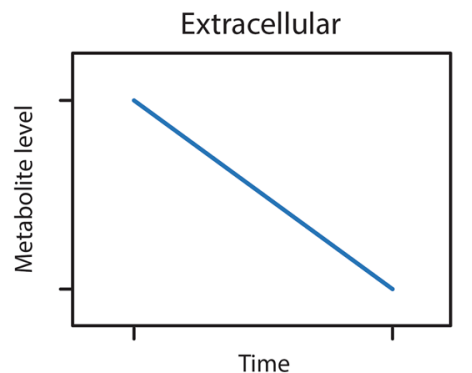

Fig. 3 Mirroring relationship patterns between intracellular and extracellular metabolite levels. a The pattern of a typical metabolic overflow where a metabolite level increases both intracellularly and extracellularly over time (e.g. 2-phenylacetic acid in Escherichia coli from Carneiro et al. 2012). b The pattern of concomitant decrease in level of a metabolite in both extracellular and intracellular samples (e.g. glycine in Saccharomyces cerevisiae from Granucci et al. 2015) a

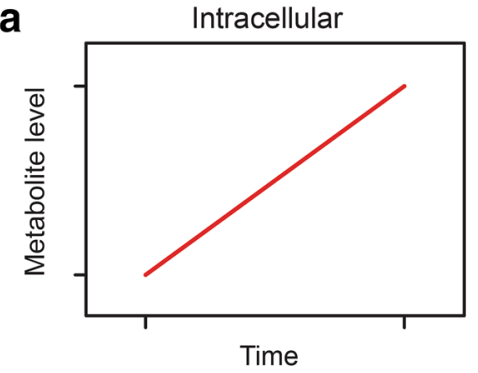

b

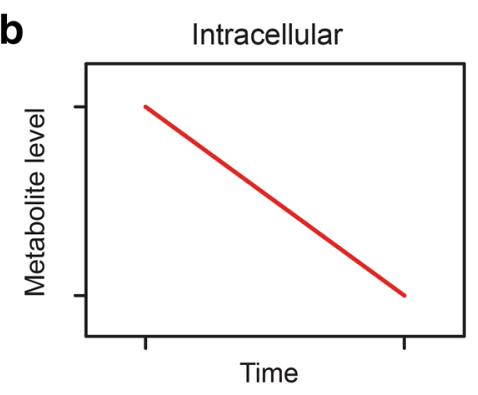

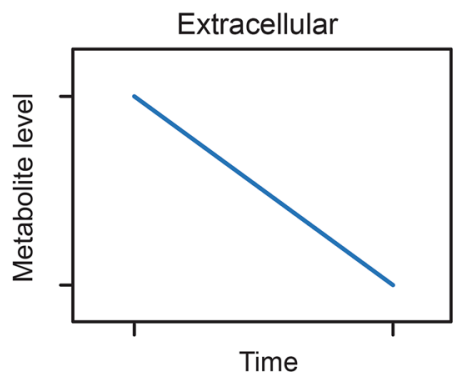

Extracellular

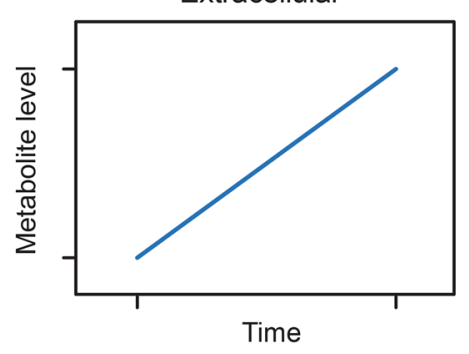

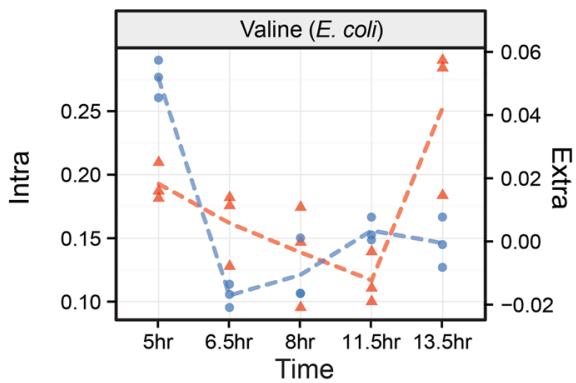

- Intra

-. Extra

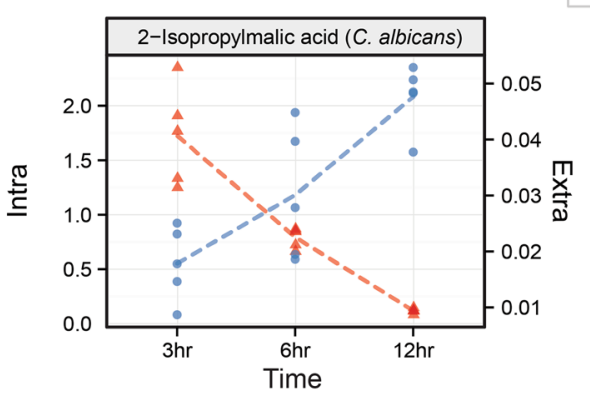

Fig. 4 Opposite patterns of level changing between intracellular and extracellular metabolites. a The increase in the intracellular level of a metabolite while its extracellular level decreases (e.g. valine in Escherichia coli from Carneiro et al. 2012). b A decrease of a metab- olite level intracellularly with concomitant increase of its level extracellularly (e.g. 2-isopropylmalic acid in Candida albicans from Han et al. 2013) 

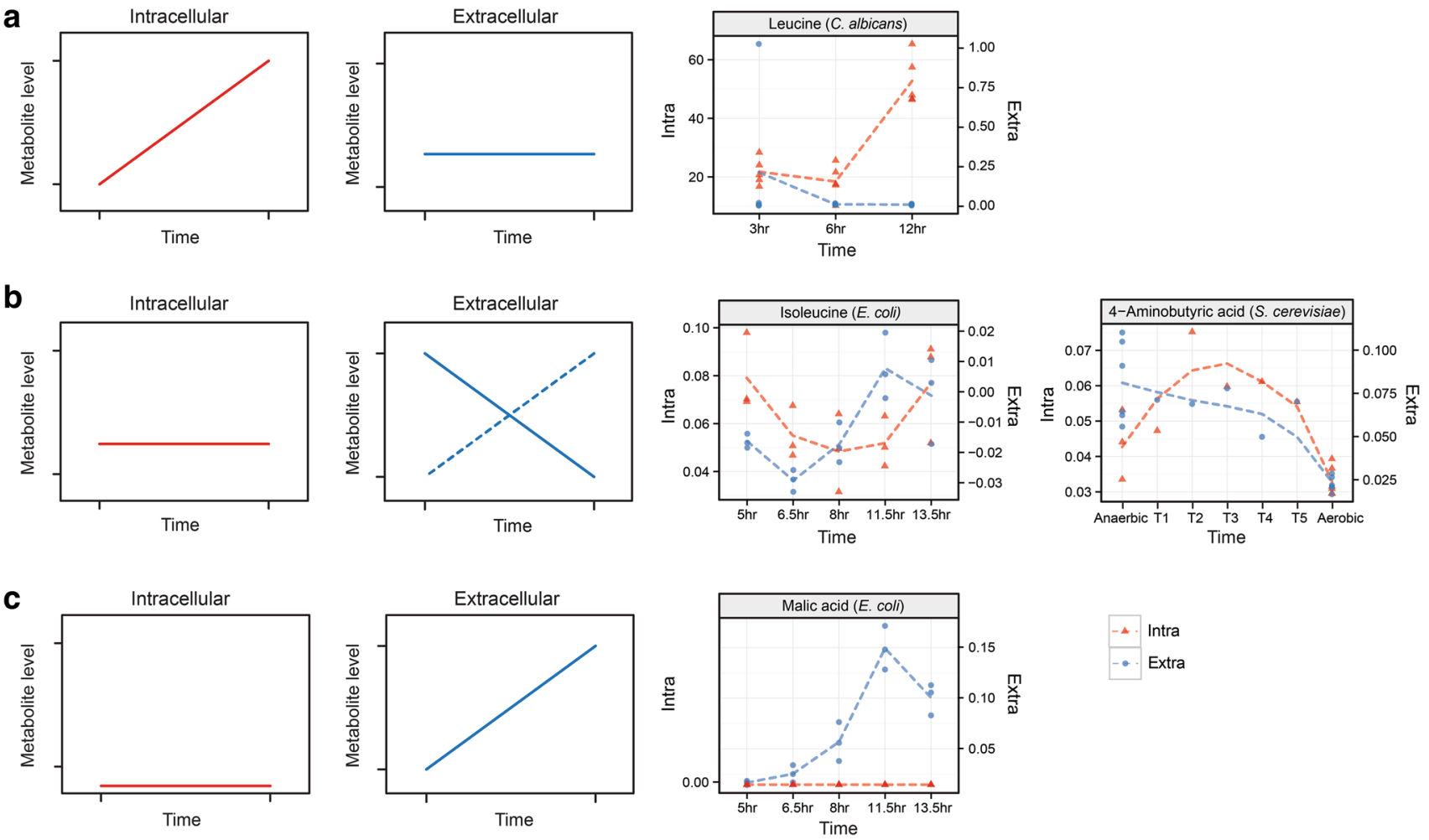

Fig. 5 Other relationship patterns between intracellular and extracellular metabolite levels. a The pattern when a metabolite level increases intracellularly with no significant change in its extracellular level (e.g. leucine levels in Candida albicans from Han et al. 2013). b The pattern when a metabolite level shows no significant change intracellularly, but its extracellular level either increases (dashed line) or decreases (solid line) (e.g. isoleucine in Escherichia coli from Carneiro et al. 2012 and 4-aminobutyric acid in Saccharomyces cerevisiae from; Granucci et al. 2015). c When a metabolite is detected only in the extracellular medium (e.g. malic acid in Escherichia coli from Carneiro et al. 2012)

measurements of intracellular metabolites (Paczia et al. 2012; Fu et al. 2014; Villas-Bôas et al. 2006). Therefore, we need to better characterize the relationship between intracellular and extracellular metabolite levels, the different ways they can be secreted, and the regulatory mechanisms involved in this process, before we can design accurate ways to predict the metabolic state of cells based on extracellular data alone. Time-series metabolomics data of both intracellular and extracellular metabolites can be a very useful dataset to be employed to achieve this goal; however, there are very few published studies in this format (Han et al. 2013; Carneiro et al. 2011; Granucci et al. 2015; Willemsen et al. 2015; Wiebe et al. 2008). Below, we highlight the different relationship patterns between intracellular and extracellular metabolites based on some published time-series metabolomics data (Supplementary Figs. 1-3).

Based on the time-series metabolomics data of Candida albicans (Han et al. 2013), E. coli (Carneiro et al. 2011), and $S$. cerevisiae (Granucci et al. 2015) cultures, we confirmed the possibility of seven basic relationship patterns between intracellular and extracellular metabolite levels, which are summarized schematically in Figs. 3, 4, 5. Often 
changes in the extracellular level of a metabolite mirror the changes happening inside the cell (Fig. 3). If the metabolite level increases both intracellularly and extracellularly, it characterizes a typical process of metabolic overflow (Fig. 3a). However, if a metabolite level decreases both intracellularly and extracellularly, it represents a reduction in its biosynthesis or increase in its intracellular turnover rate concomitantly with an increase in its uptake from the extracellular medium (Fig. 3b). On the other hand, the pattern of change in metabolite level may follow opposite directions when comparing intracellular and extracellular samples (Fig. 4). If a metabolite level increases intracellularly and decreases in the extracellular medium, it represents a typical case of metabolite uptake (Fig. 4a). But, when its level decreases intracellularly and increases in the extracellular medium, it gives strong evidence of metabolite efflux without a clear intracellular metabolic overflow (Fig. 4b). Nevertheless, frequently the level of a metabolite vary significantly inside the cell without affecting its extracellular level (Fig. 5a), suggesting an active regulation of its secretion mechanism. Conversely, the level of a metabolite may vary significantly in the extracellular medium without affecting its intracellular levels (Fig. 5b), which could result from the tight regulation of its intracellular level by the cell. The most puzzling scenario is when a metabolite produced inside the cell is detected only in the extracellular medium and its level decrease or even increase over time without it being found at detectable levels in intracellular samples (Fig. 5c). We speculate this could represent metabolites that are slowly uptaken and quickly metabolized inside the cells due to high concentration of enzymes and other metabolites (Fig. 5c dashed blue line), or they are secreted as a result of strong transporter affinity for the compounds over intracellular metabolic enzymes (Fig. 5c, full blue line). Alternatively, one cannot rule out the possibility of some metabolic reactions to take place outside the cells spontaneously or catalyzed by secreted or membrane-embedded enzymes. Nonetheless, these different patterns of metabolite secretion clearly illustrate that the change in extracellular media does not always reflect similar changes intracellularly. We also need to take into account to those out of equilibrium reactions that usually tend to have high flux control coefficient. To determine the effects of such pathway reactions on flows and on metabolite concentrations quantitatively, metabolic control analysis (MCA) has widely been used as a tool (Fell 1992; Kell and Westerhoff 1986; Moreno-Sanchez et al. 2008). Therefore, the combination of intra and extracellular metabolomics data and MCA could allow us to acquire in depth knowledge on overall metabolism of microbial cells.

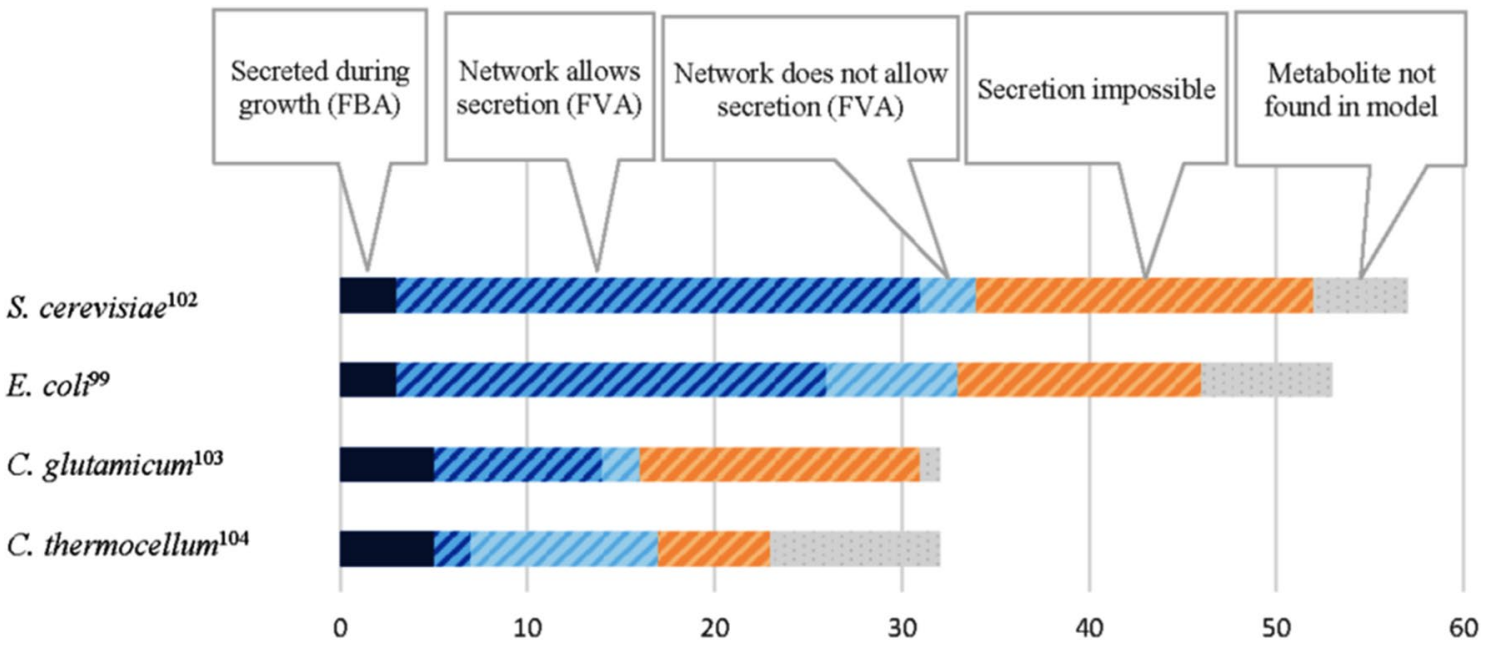

Number of experimentally measured secreted metabolites

Fig. 6 Metabolite secretion in published Saccharomyces cerevisiae (Aung et al. 2013) Escherichia coli (Orth et al. 2011) Corynebacterium glutamicum (Shinfuku et al. 2009) and Clostridium thermocellum (Roberts et al. 2010) genome-scale models. Each bar represents all metabolites reported to have been secreted during growth according to quantitative time-dependent metabolomics analysis. Each bar segment illustrates the ability of the respective genome-scale model to secrete these metabolites. Metabolic models correctly identify the secretion of $<10 \%$ of secreted metabolites during growth. Further- more, a large proportion of metabolites are structurally unable to be secreted by the metabolic network; either flux variability analysis (FVA) indicates their secretion is never possible, or the network lacks a relevant transport reaction. Finally, some secreted metabolites do not exist in the metabolic network. The experimentally measured secreted metabolites assessed in this graph are from targeted metabolomics studies; untargeted studies suggest an even greater diversity of metabolite secretion 


\section{Impact on metabolic modeling and engineering}

Metabolic engineering studies usually only consider the secretion of several compounds. However, these metabolomics studies show that hundreds of compounds are secreted into the culture broth during growth. As well as having a direct impact on metabolic engineering outcomes, their presence in the extracellular environment can provide insight into the metabolic state of a cell (Paczia et al. 2012; Mo et al. 2009; Aurich et al. 2014). Most simply, the secretion of a compound in response to intracellular accumulation suggests the existence of an imbalanced pathway, uncovering the potential metabolic engineering targets. Further insight can be gained when the mode of secretion does not conform to this classic metabolic overflow. For example, the secretion of amino acids may indicate an overabundance of nitrogen in the system, allowing the metabolic engineer to alter the metabolic network to reduce carbon leakage through amino acid secretion. Benzoic acid and hydroxybenzoic acid can be actively secreted independent of their intracellular concentration, likely because of their toxicity; this may inhibit cell growth in a bioreactor. The mechanisms behind the secretion of many metabolites require further study; with greater understanding, these processes can be more precisely identified and modulated in order to achieve a metabolic engineering goal.

Published genome-scale models do not correctly represent metabolite secretion during simulated growth. Metabolic engineers are increasingly utilizing these constraintbased models, which predict metabolic pathway fluxes (Mccloskey et al. 2013). These models link genotype to phenotype and allow microbial strain designs to be tested in silico by applying a computational method to a reconstructed metabolic network. Figure 6 summarizes the observed exometabolomes of S. cerevisiae, E. coli, C. glutamicum and Corynebacterium thermocellum under standard conditions and compares them to the predicted genome-scale model exometabolomes using flux balance analysis (FBA), a technique which predicts steady state metabolite flow based on a biological goal, usually the maximization of growth rate (Orth et al. 2011). In all cases, the model under-represents the diversity of metabolite secretion. For example, while $E$. coli model iJO1366 predicts the secretion of six metabolites, targeted analysis has quantified 34 secreted metabolites (Paczia et al. 2012). In another study, 39 metabolites were secreted and over 200 GC-MS peaks were detected during metabolic footprinting analysis, at least half of which would represent genuine extracellular metabolites based on their unique mass spectra, retention times and experiments with isotope labelled derivatizing reagents (Carneiro et al. 2011). This discrepancy between simulation and reality is because, by definition, only growth-coupled metabolite secretion will contribute to the FBA maximise biomass optimal solution recommended by most authors (Lee et al. 2012; van Berlo et al. 2011). Models can capture the overflow of common products such as acetate, ethanol and lactate because these secretions are linked to growth during simulation, often driven by the redox and energy balance. However, the secretion mechanisms of many primary metabolites under normal growth conditions have not been elucidated and must be investigated to determine if they can be predicted by FBA.

Regardless of the growth simulation method used, models are structurally unable to secrete many metabolites that have been observed extracellularly (Fig. 6). For example, glyceraldehyde-3-phosphate, dihydroxyacetone phosphate and phosphoenolpyruvate are secreted by E. coli (Paczia et al. 2012), but cannot be secreted by model iJO1366 under any condition because it lacks the relevant transport reactions (Orth et al. 2010). This omission is common across published models; none of the 93 models reviewed have the ability to secrete phosphoenolpyruvate, likely because there is no annotated transporter for this compound in any of the major reaction databases. Furthermore, some secreted compounds do not exist at all in the metabolic network reconstruction. For example, itaconate, malonate, 2-phenylglycine and benzoate can be secreted by $E$. coli, but reactions to form these are not defined in any of the relevant metabolic reconstructions or public databases (including KEGG and EcoCyc) (Carneiro et al. 2011). The solution is to incorporate reactions which account for these secretions (Mo et al. 2009). However, in some cases these enzymes or transporters do not exist in reaction databases and require elucidation. Transporters and enzymes can act in a non-specific way, catalyzing reactions beyond those they were characterized for (Notebaart et al. 2014; Guzmán et al. 2015). Techniques to identify and incorporate enzyme promiscuity into genomescale reconstructions may resolve some of these knowledge gaps (Guzmán et al. 2015).

Incorrect metabolite secretions predicted by genomescale models make up a small proportion of total metabolic flux and the overall carbon balance and their exclusion has little impact on model fitness under standard training conditions. For E. coli, these secretions represent $<1 \%$ of substrate carbon yield, with a remaining $6 \%$ gap in the experimental carbon balance assumed to be systematic error (Paczia et al. 2012). Model fitness can be calculated using mean relative error to assess predicted secretions and growth rates against experimental measurements (Perez-Garcia et al. 2014). When using this method to calculate model fitness for $E$. coli model iJO1366, the exclusion of these secretions reduces accuracy by $2.13 \%$ under normal training conditions. While the output of carbon is incorrectly distributed and leads to a systematic error in predictions, this introduced error is less than overall measurement error and can 
be considered a valid compromise when carrying out simulations using growth as an objective function.

However, the ultimate measure of the accuracy of a model is its ability to predict the flux distribution throughout the metabolic network, and recent research indicates that minor secretions can influence the predicted distribution of fluxes within the cell. Secretions can be measured and applied as constraints to a metabolic model to predict internal metabolic states. For example, Mo et al. (2009) apply secretion constraints to a yeast genome-scale model and use a flux sampling approach to successfully predict intracellular metabolic flux distributions. While researchers had previously done this in a limited way, this recent work takes into account a greater number of observed secretions by manually adding and constraining additional exchange reactions (Mo et al. 2009; Aurich et al. 2014). This work demonstrates that the incorporation of these secretions allows intracellular flux states to be predicted more accurately, despite the fact that they represent a small fraction of the overall flux. This technique is interesting because the exometabolome can be readily measured and applied to identify control points and characterize flux in different microbial strains (Aurich et al. 2014). To uncover the full power of this technique, the full exometabolomic profile can be included; however, for this to be done, transporters need to be incorporated into metabolic models in order to capture the full diversity of secretions.

Furthermore, in several metabolic engineering scenarios, the correct representation of metabolic secretion becomes important. One example is the use of genome-scale models to predict metabolic perturbations that increase product yield. Algorithms are used to assess different combinations of gene knockouts and their impact on both growth rate and product formation. If metabolite secretions are not correctly represented, inferior metabolic perturbation strategies may be recommended. For example, the elimination of a competing pathway in vivo may result in a metabolic bottleneck and the leakage of a metabolite previously secreted at low levels. Without the ability to represent this metabolite's secretion, the model will not accurately predict the outcome. Finally, this knowledge can be applied to current models by using data on metabolite secretion to define reference states when using algorithms that predict genetic perturbation. In this instance, techniques such as minimization of metabolic adjustment (MoMA), which find a solution near to the flux distribution of the unperturbed states, are better able to predict suboptimal growth associated with the secretion of metabolites (Segrè et al. 2002).

\section{Conclusions}

The most accepted theory for the secretion of metabolites is the concept of metabolic overflow (Paczia et al. 2012; Mo et al. 2009). However, time series metabolomics data reviewed here clearly indicate that intracellular metabolic overflow cannot explain the secretion of all intracellular metabolites found in spent culture media. It is not yet possible to propose any species-specific or metabolite-specific rules for secretion. Therefore, more time-series metabolomics studies, mainly involving phylogenetically close species, are necessary to understand better the relationship between intracellular and extracellular metabolite levels. Moreover, a special attention also need to be paid on developing more methods for acquiring quantitative data and also on better experimental design. We also recommend that the metabolic engineering community takes into consideration both the large number of secretions which can occur during the different phases of microbial growth and the unique mechanisms through which these can occur, often not conforming to the standard theory of metabolic overflow. As well as having a direct impact on metabolic engineering outcomes, their presence in the extracellular environment can provide insight into the metabolic state of a cell. Many mechanisms of secretion still require elucidation before secretion can be predicted by metabolic models. However, the presence of a metabolite in the exometabolome indicates that relevant reactions should be included in the network reconstruction, and these can be constrained using intracellular and extracellular metabolomics data to predict intracellular flux states. Future study should focus on identifying these mechanisms, and their fit within the framework of predictive constraint-based modeling techniques, to allow predictions to be made. Within these scenarios transport fluxes can be quantified using ${ }^{13} \mathrm{C}$-labelling studies.

Acknowledgements The authors are thankful to Mia Jüllig for assistance with Fig. 2. Callaghan Innovation and Bioresource Processing Alliance provided $\mathrm{PhD}$ stipends for James Daniell and Ninna Granucci respectively.

\section{Compliance with ethical standards}

Conflict of interest The authors declare that the research was conducted in the absence of any commercial or financial relationships that could be construed as a potential conflict of interest.

\section{References}

Agarwal, L., Isar, J., Meghwanshi, G. K., \& Saxena, R. K. (2006). A cost effective fermentative production of succinic acid from cane molasses and corn steep liquor by Escherichia coli. Journal of Applied Microbiology, 100, 1348-1354. https://doi.org/10.111 1/j.1365-2672.2006.02894.x.

Airich, L. G., Tsyrenzhapova, I. S., Vorontsova, O. V., Feofanov, A. V., Doroshenko, V. G., \& Mashko, S. V. (2010). Membrane topology analysis of the Escherichia coli aromatic amino acid efflux protein YDDG. Journal of Molecular Microbiology and Biotechnology, 19, 189-197. https://doi.org/10.1159/000320699. 
Ajinomoto. (2009). Fact Sheet: Amino Acids Business [online]. 2015. Retrieved August 19, 2002 from https://www.ajinomoto.com/en/. Accessed 10 Oct 2017.

Allen, J., Davey, H.M., Broadhurst, D., Heald, J.K., Rowland, J.J., Oliver, S.G., et al. (2003). High-throughput classification of yeast mutants for functional genomics using metabolic footprinting. Nature Biotechnology, 21, 692-696.

Aung, H. W., Henry, S. A., \& Walker, L. P. (2013). Revising the representation of fatty acid, glycerolipid, and glycerophospholipid metabolism in the consensus model of yeast metabolism. Industrial Biotechnology, 9, 215-228. https://doi.org/10.1007/s1130 6-014-0721-3.

Aurich, M. K., Paglia, G., Rolfsson, Ó, Hrafnsdóttir, S., Magnúsdóttir, M., Stefaniak, M. M., et al. (2014). Prediction of intracellular metabolic states from extracellular metabolomic data. Metabolomics, 11, 603-619. https://doi.org/10.1007/s1130 6-014-0721-3.

Bass, R. B., Strop, P., Barclay, M., \& Rees, D. C. (2002). Crystal structure of Escherichia coli $\mathrm{MscS}$, a voltage-modulated and mechanosensitive channel. Science, 298, 1582-1587. https:// doi.org/10.1126/science.1077945.

Becker, M., Börngen, K., Nomura, T., Battle, A. R., Marin, K., Martinac, B., et al. (2013). Glutamate efflux mediated by Corynebacterium glutamicum MSCCG, Escherichia coli MSCS, and their derivatives. BBA-Biomembrane, 1828, 1230-1240. https://doi. org/10.1016/j.bbamem.2013.01.001.

Beese-Sims, S. E., Lee, J., \& Levin, D. E. (2011). Yeast Fps1 glycerol facilitator functions as a homotetramer. Yeast, 28, 815-819. https ://doi.org/10.1002/yea.1908.

Börngen, K., Battle, A. R., Möker, N., Morbach, S., Marin, K., Martinac, B., et al. (2010). The properties and contribution of the Corynebacterium glutamicum MSCS variant to fine-tuning of osmotic adaptation. BBA-Biomembrane, 1798, 2141-2149. https ://doi.org/10.1016/j.bbamem.2010.06.022.

Boudker, O., \& Verdon, G. (2010). Structural perspectives on secondary active transporters. Trends in Pharmacological Science, 31, 418-426. https://doi.org/10.1016/j.tips.2010.06.004.

Braga, R. M., Dourado, M. N., \& Araujo, W. L. (2016). Microbial interactions: Ecology in a molecular perspective. Brazilian Journal of Microbiology, 47, 86-98.

Broda, P. (1968). Ribonucleic acid synthesis and glutamate excretion in Escherichia coli. Journal of Bacteriology, 96, 1528-1534.

Burkovski, A., \& Krämer, R. (2002). Bacterial amino acid transport proteins: Occurrence, functions, and significance for biotechnological applications. Applied Microbiology and Biotechnology, 58, 265-274. https://doi.org/10.1007/s00253-001-0869-4.

Carneiro, S., Villas-Bôas, S. G., Ferreira, E. C., \& Rocha, I. (2011). Metabolic footprint analysis of recombinant Escherichia coli strains during fed-batch fermentations. Molecular Biosystems, 7, 899-910. https://doi.org/10.1039/c0MB00143k.

Carneiro, S., Villas-Bôas, S. G., Ferreira, E. C., \& Rocha, I. (2012). Influence of the RelA activity on E. coli metabolism by metabolite profiling of glucose-limited chemostat cultures. Metabolites, 2, 717-732. https://doi.org/10.3390/metabo2040717.

Chubukov, V., Gerosa, L., Kochanowski, K., \& Sauer, U. (2014). Coordination of microbial metabolism. Nature Reviews Microbiology, 12, 327-340. https://doi.org/10.1038/nrmicro3238.

Chumnanpuen, P., Hansen, M. A. E., Smedsgaard, J., \& Nielsen, J. (2014). Dynamic metabolic footprinting reveals the key components of metabolic network in yeast Saccharomyces cerevisiae. International Journal of Genomics 2014: Article ID 894296. https://doi.org/10.1155/2014/894296.

Cocaign-Bousquet, M., \& Lindley, N. D. (1995). Pyruvate overflow and carbon flux within the central metabolic pathways of Corynebacterium glutamicum during growth on lactate.
Enzyme and Microbial Technology, 17, 260-267. https://doi. org/10.1016/0141-0229(94)00023-K.

Crabtree, H. G. (1929). Observations on the carbohydrate metabolism of tumours. Biochemical Journal, 23, 536-545.

Daßler, T., Maier, T., Winterhalter, C., \& Böck, A. (2000). Identification of a major facilitator protein from Escherichia coli involved in efflux of metabolites of the cysteine pathway. Molecular Microbiology, 36, 1101-1112.

Dörries, K., \& Lalk, M. (2013). Metabolic footprint analysis uncovers strain specific overflow metabolism and d-isoleucine production of Staphylococcus aureus COL and HG001. PLoS ONE. https:// doi.org/10.1371/journal.pone.0081500.

dos Santos, S. C., \& Sa-Correia, I. (2011). A genome-wide screen identifies yeast genes required for protection against or enhanced cytotoxicity of the antimalarial drug quinine. Molecular Genetics and Genomics, 286, 333-346.

dos Santos, S. C., \& Sa-Correia, I. (2015). Yeast toxicogenomics: Lessons from a eukaryotic cell model and cell factory. Current Opinion in Biotechnology, 33, 183-191.

dos Santos, S. C., Teixeira, M. C., Dias, P. J., \& Sa-Correia, I. (2014). MFS transporters required for multidrug/multixenobiotic (MD/ MX) resistance in the model yeast: Understanding their physiological function through post-genomic approaches. Frontiers in Physiology, 5, 180.

Driessen, A. J. M., \& Konings, W.,N. (1990). Energetic problems of bacterial fermentations extrusion of metabolic end products. In T. A. Krulwich (Ed.), The bacteria: A treatise on structure and function. San Diego: Academic Press, Inc.

Düring-Olsen, L., Regenberg, B., Gjermansen, C., Kielland-Brandt, M. C., \& Hansen, J. (1999). Cysteine uptake by Saccharomyces cerevisiae is accomplished by multiple permeases. Current Genetics, 35, 609-617.

Eggeling, L., \& Sahm, H. (2003). New ubiquitous translocators: Amino acid export by Corynebacterium glutamicum and Escherichia coli. Archives of Microbiology, 180, 155-160. https://doi. org/10.1007/s00203-003-0581-0.

Fell, D. A. (1992). Metabolic control analysis-A survey of its theoretical and experimental development. Biochemical Journal, 286, 313-330.

Forrest, L. R., Krämer, R., \& Ziegler, C. (2011). The structural basis of secondary active transport mechanisms. BBA-Bioenergetics, 1807, 167-188. https://doi.org/10.1016/j.bbabio.2010.10.014.

Forsberg, H., \& Ljungdahl, P. O. (2001). Sensors of extracellular nutrients in Saccharomyces cerevisiae. Current Genetics, 40, 91-109. https://doi.org/10.1007/s002940100244.

Franke, S., Grass, G., Rensing, C., \& Nies, D. H. (2003). Molecular analysis of the copper-transporting efflux system cuscfba of Escherichia coli. Journal of Bacteriology, 185, 3804-3812. https ://doi.org/10.1128/JB.185.13.3804-3812.2003.

Fu, Z., Verderame, T. D., Leighton, J. M., Sampey, B. P., Appelbaum, E. R., Patel, P. S., et al. (2014). Exometabolome analysis reveals hypoxia at the up-scaling of a Saccharomyces cerevisiae highcell density fed-batch biopharmaceutical process. Microbial Cell Factories, 13, 32. https://doi.org/10.1186/1475-2859-13-32.

Fukui, K., Koseki, C., Yamamoto, Y., Nakamura, J., Sasahara, A., Yuji, R., et al. (2011). Identification of succinate exporter in Corynebacterium glutamicum and its physiological roles under anaerobic conditions. Journal of Bacteriology, 154, 25-34. https ://doi.org/10.1016/j.jbiotec.2011.03.010.

Geijer, C., Ahmadpour, D., Palmgren, M., Filipsson, C., Klein, D. M., et al. (2012). Yeast aquaglyceroporins use the transmembrane core to restrict glycerol transport. Journal of Biological Chemistry, 287, 23562-23570. https://doi.org/10.1074/jbc.M112.35348 2.

Granucci, N., Pinu, F. R., Han, T. L., \& Villas-Boas, S. G. (2015). Can we predict the intracellular metabolic state of a cell based 
in extracellular metabolite data? Molecular BioSystems, 11, 3297-3304. https://doi.org/10.1039/C5MB00292C.

Guzmán, G. I., Utrilla, J., Nurk, S., Brunk, E., Monk, J. M., Ebrahim, A., et al. (2015). Model-driven discovery of underground metabolic functions in Escherichia coli. Proceedings of National Academy of Science of the United States of America 112, 929 934. https://doi.org/10.1073/pnas.1414218112.

Hagman, A., Säll, T., \& Piškur, J. (2014). Analysis of the yeast shortterm crabtree effect and its origin. FEBS Journal, 281, 48054814. https://doi.org/10.1111/febs.13019.

Han, T. L., Tumanov, S., Cannon, R. D., \& Villas-Boas, S.,G. (2013). Metabolic response of Candida albicans to phenylethyl alcohol under hyphae-inducing conditions. PLOS ONE. https://doi. org/10.1371/journal.pone.0071364.

Hermann, T., \& Krämer, R. (1996). Mechanism and regulation of isoleucine excretion in Corynebacterium glutamicum. Applied and Environmental Microbiology, 62, 3238-3244.

Hoffmann, T., Von Blohn, C., Stanek, A., Moses, S., Barzantny, H., \& Bremer, E. (2012). Synthesis, release, and recapture of compatible solute proline by osmotically stressed Bacillus subtilis cells. Applied and Environmental Microbiology, 78, 5753-5762. https ://doi.org/10.1128/AEM.01040-12.

Holme, T. (1957). Continuous culture studies on glycogen synthesis in Escherichia coli B. Acta Chemica Scandenavica, 11, 763-775.

Ingram, L. O. (1976). Adaptation of membrane lipids to alcohols. Journal of Bacteriology, 125, 670-678.

Kell, D. B., Brown, M., Davey, H. M., Dunn, W. B., Spasic, I., \& Oliver, S. G. (2005). Metabolic footprinting and systems biology: The medium is the message. Nature Reviews Microbiology, 3, 557-565. https://doi.org/10.1038/nrmicro1177.

Kell, D. B., \& Oliver, S. G. (2014). How drugs get into cells: Tested and testable predictions to help discriminate between transportermediated uptake and lipoidal bilayer diffusion. Frontiers in Pharmacology, 5, 231.

Kell, D. B., Peck, M. W., Rodger, G., \& Morris, J. G. (1981). On the permeability to weak acids and bases of the cytoplasmic membrane of Clostridium pasteurianum. Biochemical and Biophysical Research Communications, 99(1), 81-88.

Kell, D. B., Swainston, N., Pir, P., \& Oliver, S. G. (2015). Membrane transporter engineering in industrial biotechnology and whole cell biocatalysis. Trends in Biotechnology, 33, 237-246.

Kell, D. B., \& Westerhoff, H. V. (1986). Metabolic control-theory-Its role in microbiology and biotechnology. Fems Microbiology Letters, 39, 305-320.

Kiefer, P., Heinzle, E., Zelder, O., \& Wittmann, C. (2004). Comparative metabolic flux analysis of lysine-producing Corynebacterium glutamicum cultured on glucose or fructose. Applied and Environmental Microbiology, 70, 229-239. https://doi.org/10.1128/ AEM.70.1.229-239.2004.

Kinclova-Zimmermannova, O., \& Sychrova, H. (2007). Plasma-membrane $\mathrm{Cnh} 1 \mathrm{Na} / \mathrm{H}$ antiporter regulates potassium homeostasis in Candida albicans. Microbiology, 153, 2603-2612. https://doi. org/10.1099/mic.0.2007/008011-0.

Konings, W. N., Poolman, B., \& Driessen, A. M. (1992). Can the excretion of metabolites by bacteria be manipulated? FEMS Microbiology Letters, 88:, 93-108. https://doi. org/10.1111/j.1574-6968.1992.tb04959.x.

Krämer, R. (1994). Secretion of amino acids by bacteria: Physiology and mechanism. FEMS Microbiology Reviews, 13, 75-94. https ://doi.org/10.1111/j.1574-6976.1994.tb00036.x.

Krämer, R. (1996). Analysis and modeling of substrate uptake and product release by prokaryotic and eukaryotic cells. Advances in Biochemical Engineering and Biotechnology, 54, 31-74.

Krämer, R. (2004). Production of amino acids: Physiological and genetic approaches. Food Biotechnology, 18, 171-216. https:// doi.org/10.1081/FBT-200025664.
Kubicek, C. P. (1987). The role of the citric acid cycle in fungal organic acid fermentations. Biochemical Society Symposium, $54,113-126$.

Lamark, T., Styrvold, O. B., \& Strøm, A. R. (1992). Efflux of choline and glycine betaine from osmoregulating cells of Escherichia coli. FEMS Microbiology Letters, 96, 149-154. https://doi. org/10.1016/0378-1097(92)90395-5.

Lee, D., Smallbone, K., Dunn, W.B., Murabito, E., Winder, C.L., Kell, D.B., et al. (2012). Improving metabolic flux predictions using absolute gene expression data. BMC Systems Biology, 6, 73.

Legiša, M., \& Mattey, M. (2007). Changes in primary metabolism leading to citric acid overflow in Aspergillus niger. Biotechnology Letters, 29, 181-190. https://doi.org/10.1007/s1052 9-006-9235-z.

Lepore, B. W., Indic, M., Pham, H., Hearn, E. M., Patel, D. R., \& van den Berg, B. (2011). Ligand-gated diffusion across the bacterial outer membrane. Proceedings of the National Academy of Sciences of the United States of America, 108, 10121-10126.

Liang, L., Liu, R., Li, F., Wu, M., Chen, K., Ma, J., et al. (2013). Repetitive succinic acid production from lignocellulose hydrolysates by enhancement of atp supply in metabolically engineered Escherichia coli. Bio resource Technology, 143, 405412. https://doi.org/10.1016/j.biortech.2013.06.031.

Liu, J. Y., Miller, P. F., Willard, J., \& Olson, E. R. (1999). Functional and biochemical characterization of Escherichia coli sugar efflux transporters. Journal of Biological Chemistry, 274, $22977-$ 22984. https://doi.org/10.1074/jbc.274.33.22977.

Livshits, V. A., Zakataeva, N. P., Aleshin, V. V., \& Vitushkina, M. V. (2003). Identification and characterization of the new gene rhta involved in threonine and homoserine efflux in Escherichia coli. Research in Microbiology, 154, 123-135. https://doi. org/10.1016/S0923-2508(03)00036-6.

Ljungdahl, P. O., \& Daignan-Fornier, B. (2012). Regulation of amino acid, nucleotide, and phosphate metabolism in Saccharomyces cerevisiae. Genetics, 190, 885-929. https://doi.org/10.1534/genet ics.111.133306.

Magasanik, B., \& Kaiser, C. A. (2002). Nitrogen regulation in Saccharomyces cerevisiae. Gene, 290, 1-18. https://doi.org/10.1016/ S0378-1119(02)00558-9.

Martín, J. F., Casqueiro, J., \& Liras, P. (2005). Secretion systems for secondary metabolites: How producer cells send out messages of intercellular communication. Current Opinion on Microbiology, 8, 282-293. https://doi.org/10.1016/j.mib.2005.04.009.

Mattey, M. (1992). The production of organic acids. Critical Reviews on Biotechnology, 12, 87-132. https://doi.org/10.3109/07388 559209069189.

Mccloskey, D., Palsson, B. O., \& Feist, A. M. (2013). Basic and applied uses of genome-scale metabolic network reconstructions of Escherichia coli. Molecular System Biology, 9, 661. https://doi. org/10.1038/msb.2013.18.

Mitsuhashi, S. (2014). Current topics in the biotechnological production of essential amino acids, functional amino acids, and dipeptides. Current Opinion in Biotechnology, 26, 38-44.

Mo, M. L., Palsson, B., \& Herrgård, M. J. (2009). Connecting extracellular metabolomic measurements to intracellular flux states in yeast. BMC System Biology. https://doi. org/10.1186/1752-0509-3-37.

Molenaar, D., Van Berlo, R., De Ridder, D., \& Teusink, B. (2009). Shifts in growth strategies reflect tradeoffs in cellular economics. Molecular System Biology, 5, 323. https://doi.org/10.1038/ msb.2009.82.

Moreno-Sanchez, R., Saavedra, E., Rodriguez-Enriquez, S., \& OlinSandoval, V. (2008). Metabolic control analysis: A tool for designing strategies to manipulate metabolic pathways. Journal of Biomedicine and Biotechnology, 2008: 597913. 
Nakamura, J., Hirano, S., Ito, H., \& Wachi, M. (2007). Mutations of the Corynebacterium glutamicum ncgl1221 gene, encoding a mechanosensitive channel homolog, induce l-glutamic acid production. Applied and Environmental Microbiology, 73, 4491-4498. https ://doi.org/10.1128/AEM.02446-06.

Nehls, U., Mikolajewski, S., Magel, E., \& Hampp, R. (2001). Carbohydrate metabolism in ectomycorrhizas: Gene expression, monosaccharide transport and metabolic control. New Phytologist, 150, 533-541. https://doi.org/10.1046/j.1469-8137.2001.00141 .x.

Neijssel, O. M., \& Tempest, D. W. (1975). Production of gluconic acid and 2 ketogluconic acid by Klebsiella aerogenes NCTC 418. Archives in Microbiology, 105, 183-185.

Neijssel, O. M., \& Tempest, D. W. (1976). Role of energy-spilling reactions in growth of klebsiella-aerogenes NCTC-418 in aerobic chemostat culture. Archives of Microbiology, 110, 305-311.

Netik, A., Torres, N. V., Riol, J. M., \& Kubicek, C. P. (1997). Uptake and export of citric acid by Aspergillus niger is reciprocally regulated by manganese ions. BBA-Biomembranes, 1326, 287-294. https://doi.org/10.1016/S0005-2736(97)00032-1.

Nikaido, H. (1993). Transport across the bacterial outer-membrane. Journal of Bioenergetics and Biomembranes, 25, 581-589.

Notebaart, R. A., Szappanos, B., Kintses, B., Pál, F., Györkei, Á, \& Bogos, B., et al. (2014). Network-level architecture and the evolutionary potential of underground metabolism. Proceedings of National Academy of Science of the United States of America 111, 11762-11767. https://doi.org/10.1073/pnas.1406102111.

Orth, J. D., Conrad, T. M., Na, J., Lerman, J. A., Nam, H., Feist, A. M., et al. (2011). A comprehensive genome-scale reconstruction of Escherichia coli metabolism-2011. Molecular System Biology, 7, 535. https://doi.org/10.1038/msb.2011.65.

Orth, J. D., Thiele, I., \& Palsson, B. O. (2010). What is flux balance analysis? Nature Biotechnology, 28, 245-248. https://doi. org/10.1038/nbt.1614.

Paczia, N., Nilgen, A., Lehmann, T., Gätgens, J., Wiechert, W., \& Noack, S. (2012). Extensive exometabolome analysis reveals extended overflow metabolism in various microorganisms. Microbial Cell Factories, 11, 122. https://doi. org/10.1186/1475-2859-11-122.

Perez-Garcia, O., Villas-Boas, S. G., \& Singhal, N. (2014). A method to calibrate metabolic network models with experimental datasets. 8th International Conference on Practical Applications of Computational Biology and Bioinformatics, PACCB 2014, 294, 183-190. https://doi.org/10.1007/978-3-319-07581-5_22.

Pinu, F. R., \& Villas-Boas, S. G. (2017). Extracellular microbial metabolomics: The state of the art. Metabolites, 7, 3 .

Ponomarova, O., \& Patil, K. R. (2015). Metabolic interactions in microbial communities: Untangling the Gordian knot. Current Opinion in Microbiology, 27, 37-44.

Poole, K. (2004). Efflux-mediated multiresistance in gram-negative bacteria. Clinical Microbiology and Infection, 10, 12-26. https ://doi.org/10.1111/j.1469-0691.2004.00763.x.

Pronk, J. T., Steensma, H. Y., \& Van Dijken, J. P. (1996). Pyruvate metabolism in Saccharomyces cerevisiae. Yeast, 12, 1607-1633. https://doi.org/10.1002/(SICI)1097-0061(19961 2)12:16<1607::AID-YEA70>3.0.CO;2-4

Rancourt, D. E., Stephenson, J. T., \& Vickell, G. A. (1984). Proline excretion by Escherichia coli K12. Biotechnology and Bioengineering, 26, 74-80. https://doi.org/10.1002/bit.260260114.

Reaves, M. L., Young, B. D., Hosios, A. M., Xu, Y. F., \& Rabinowitz, J. D. (2013). Pyrimidine homeostasis is accomplished by directed overflow metabolism. Nature, 500, 237-241. https:// doi.org/10.1038/nature12445.

Roberts, S. B., Gowen, C. M., Brooks, J. P., \& Fong, S. S. (2010). Genome-scale metabolic analysis of Clostridium thermocellum for bioethanol production. BMC System Biology, 4, 31. https:// doi.org/10.1186/1752-0509-4-31.

Saier, M. H., Jr. (2000). A functional-phylogenetic classification system for transmembrane solute transporters. Microbiology and Molecular Biology Reviews, 64, 354-411. https://doi. org/10.1128/MMBR.64.2.354-411.2000.

Saier, M. H., Jr., Tran, C. V., \& Barabote, R. D. (2006). TCDB: The transporter classification database for membrane transport protein analyses and information. Nucleic Acids Research, 34, D181-D186. https://doi.org/10.1093/nar/gkj001.

Schink, B. (2002). Synergistic interactions in the microbial world. Antonie Van Leeuwenhoek International Journal of General and Molecular Microbiology, 81, 257-261.

Schweikhard, E. S., \& Ziegler, C. M. (2012). Amino acid secondary transporters: Toward a common transport mechanism. Current Topics in Membranes, 70, 1-28. https://doi.org/10.1016/B9780-12-394316-3.00001-6.

Segrè, D., Vitkup, D., \& Church, G. M. (2002). Analysis of optimality in natural and perturbed metabolic networks. Proceedings of National Academy of Science of the United States of America, 99, 15112-15117. https://doi.org/10.1073/pnas.232349399.

Segura, A., Molina, L., Fillet, S., Krell, T., Bernal, P., Muñoz-Rojas, J., et al. (2012). Solvent tolerance in gram-negative bacteria. Current Opinion in Biotechnology, 23, 415-421. https://doi. org/10.1016/j.copbio.2011.11.015.

Shankaranand, V. S., \& Lonsane, B. K. (1994). Ability of Aspergillus niger to tolerate metal ions and minerals in a solid-state fermentation system for the production of citric acid. Process Biochemistry, 29, 29-37. https://doi.org/10.1016/0032-9592(94)80056-1.

Shinfuku, Y., Sorpitiporn, N., Sono, M., Furusawa, C. T. H., \& Shimizu, H. (2009). Development and experimental verification of a genome-scale metabolic model for Corynebacterium glutamicum. Microbial Cell Factories, 8, 43. https://doi. org/10.1186/1475-2859-8-43.

Shlykov, M. A., Zheng, W. H., Wang, E., Nguyen, J. D., \& Saier, M. H., Jr. (2013). Transmembrane molecular transporters facilitating export of molecules from cells and organelles. In E. W. Yu, Q. Zhang \& M. H. Brown (Eds.), Microbial efflux pumps: Current research. Norfolk: Caister Academic Press.

Simic, P., Sahm, H., \& Eggeling, L. (2001). L-threonine export: Use of peptides to identify a new translocator from Corynebactedum glutamicum. Journal of Bacteriology, 183, 5317-5324. https:// doi.org/10.1128/JB.183.18.5317-5324.2001.

Smith, D., Artursson, P., Avdeef, A., Di, L., Ecker, G.F., Faller, B., et al. (2014). Passive lipoidal diffusion and carrier-mediated cell uptake are both important mechanisms of membrane permeation in drug disposition. Molecular Pharmaceutics, 11, 1727-1738.

Soccol, C. R., Vandenberghe, L. P. S., Rodrigues, C., \& Pandey, A. (2006). New perspectives for citric acid production and application. Food Technology and Biotechnology, 44, 141-149.

Sonenshein, A. L. (2007). Control of key metabolic intersections in Bacillus subtilis. Nature Reviews Microbiology, 5, 917-927. https://doi.org/10.1038/nrmicro1772.

Stäbler, N., Oikawa, T., Bott, M., \& Eggeling, L. (2011). Corynebacterium glutamicum as a host for synthesis and export of d-amino acids. Journal of Bacteriology, 193,, 1702-1709. https://doi. org/10.1128/JB.01295-10.

Tempest, D. W., \& Neijssel, O. M. (1979). Overflow metabolism in aerobic micro-organisms. Biochemical Society Transactions, 7, $82-85$.

Trötschel, C., Deutenberg, D., Bathe, B., Burkovski, A., \& Krämer, R. (2005). Characterization of methionine export in Corynebacterium glutamicum. Journal of Bacteriology, 187, 3786-3794. https://doi.org/10.1128/JB.187.11.3786-3794.2005.

Valgepea, K., Adamberg, K., Nahku, R., Lahtvee, P., Arike, L., \& Vilu, R. (2010). Systems biology approach reveals that overflow 
metabolism of acetate in Escherichia coli is triggered by carbon catabolite repression of acetyl-CoA synthetase. BMC System Biology. https://doi.org/10.1186/1752-0509-4-166.

van Berlo, R. J. P., de Ridder, D., Daran, J. M., Daran-Lapujade, P. A. S., Teusink, B., \& Reinders, M. J. T. (2011). Predicting metabolic fluxes using gene expression differences as constraints. IEEEACM Transactions on Computational Biology and Bioinformatics, 8, 206-216.

Van Dyk, T. K. (2008). Bacterial efflux transport in biotechnology. Advanced Applied Microbiology, 63, 231-247. https://doi. org/10.1016/S0065-2164(07)00006-8.

Van Dyk, T. K., Templeton, L. J., Cantera, K. A., Sharpe, P. L., \& Sariaslani, F. S. (2004). Characterization of the Escherichia coli AAEAB efflux pump: A metabolic relief valve? Journal of Bacteriology, 186, 7196-7204. https://doi.org/10.1128/ JB.186.21.7196-7204.2004.

Van Hoek, M. J. A., \& Merks, R. M. H. (2012). Redox balance is key to explaining full vs. Partial switching to lowyield metabolism. BMC System Biology, 6, 22. https://doi. org/10.1186/1752-0509-6-22.

Velasco, I., Tenreiro, S., Calderon, I. L., \& André, B. (2004). Saccharomyces cerevisiae Aqr1 is an internal-membrane transporter involved in excretion of amino acids. Eukaryotic Cell, 3, 14921503. https://doi.org/10.1128/EC.3.6.1492-1503.2004.

Vemuri, G. N., Altman, E., Sangurdekar, D. P., Khodursky, A. B., \& Eiteman, M. A. (2006a). Overflow metabolism in Escherichia coli during steady-state growth: Transcriptional regulation and effect of the redox ratio. Applied and Environmental Microbiology, 72, 3653-3661. https://doi.org/10.1128/ AEM.72.5.3653-3661.2006.

Vemuri, G. N., Eiteman, M. A., \& Altman, E. (2006b). Increased recombinant protein production in Escherichia coli strains with overexpressed water-forming NADH oxidase and a deleted ARCA regulatory protein. Biotechnology and Bioengineering, 94, 538-542. https://doi.org/10.1002/bit.20853.

Verkhovskaya, M. L., Barquera, B., \& Wikström, M. (2001). Deletion of one of two Escherichia coli genes encoding putative $\mathrm{Na} / \mathrm{H}$ exchangers (ycgO) perturbs cytoplasmic alkali cation balance at low osmolarity. Microbiology, 147, 3005-3013. https://doi. org/10.1099/00221287-147-11-3005
Villas-Bôas, S. G., Moon, C. D., Noel, S., Hussein, H., Kelly, W. J., et al. (2008). Phenotypic characterization of transposon-inserted mutants of Clostridium proteoclasticum B316T using extracellular metabolomics. Journal of Bacteriology, 134, 55-63. https ://doi.org/10.1016/j.jbiotec.2008.01.010.

Villas-Bôas, S. G., Noel, S., Lane, G. A., Attwood, G., \& Cookson, A. (2006). Extracellular metabolomics: A metabolic footprinting approach to assess fiber degradation in complex media. Analytical Biochemistry, 349, 297-305. https://doi.org/10.1016/j. ab.2005.11.019.

Vrljic, M., Sahm, H., \& Eggeling, L. (1996). A new type of transporter with a new type of cellular function: L-lysine export from Corynebacterium glutamicum. Molecular Microbiology, 22, 815-826. https://doi.org/10.1046/j.1365-2958.1996.01527.x.

Wachi, M. (2013). Amino acid exporters in Corynebacterium glutamicum. In H. Yukawa \& M. Inui (Eds.), Corynebacterium glutamicum. Berlin: Springer.

Walter, A., \& Gutknecht, J. (1984). Monocarboxylic acid permeation through lipid bilayer membranes. Journal of Membrane Biology, 77, 255-264. https://doi.org/10.1007/BF01870573.

Wendisch, V. F., Bott, M., \& Eikmanns, B. J. (2006). Metabolic engineering of Escherichia coli and Corynebacterium glutamicum for biotechnological production of organic acids and amino acids. Current Opinion in Microbiology, 9, 268-274. https:// doi.org/10.1016/j.mib.2006.03.001.

West, I. C. (1997). Ligand conduction and the gated-pore mechanism of transmembrane transport. BBA-Review Biomembranes, 1331, 213-234. https://doi.org/10.1016/S0304-4157(97)00007-5.

Wiebe, M. G., Rintala, E., Tamminen, A., Simolin, H., Salusjärvi, L., \& Toivari, M., et al. (2008). Central carbon metabolism of Saccharomyces cerevisiae in anaerobic, oxygen-limited and fully aerobic steady-state conditions and following a shift to anaerobic conditions. FEMS Yeast Research, 8, 140-154. https://doi.org/1 0.1111/j.1567-1364.2007.00234.x.

Willemsen, A. M., Hendrickx, D. M., Hoefsloot, H. C. J., Hendriks, M. M. W. B., Wahl, S. A., Teusink, B., et al. (2015). METDFBA: Incorporating time-resolved metabolomics measurements into dynamic flux balance analysis. Molecular Biosystems, 11, 137-145. https://doi.org/10.1039/c4mb00510d. 